\title{
EDITORIAL
}

\section{Vitamin D and the scientific calcium dogma: understanding the 'Panacea' of the sun}

\author{
European Journal of Clinical Nutrition (2012) 66, 1080-1081; \\ doi:10.1038/ejen.2012.78
}

The concept of systemic calcium regulation as the main action of vitamin $D$ was developed nearly 1 century ago. It is still widely accepted, despite challenging evidence against it.

From a simple prescientific view, it is puzzling that the hormone of sunshine, vitamin $D$, would regulate mainly calcium, considering the intuitive and comprehensive appreciation of the sun in all religions, ${ }^{1}$ the holistic health aspects of Yin-Yang and Greek and Renaissance heliotherapy. Why, this question needs to be asked, did the modern scientific process become preoccupied with just one aspect of sunshine and for so long-singling out ultraviolet, neglecting other wavelengths of the spectrum and singularly focusing on vitamin D and its calcium effects? Apparently, the scientific focus on calcium was fostered by easily observed bone alterations, supported by expedient diagnostic methods and charged by a mindset that powerful scientist experts developed, played up and guarded, with neglect and even denigration of non-calcitropic effects, not recognizing what they studied and promoted was related only to the tail of the elephant. ${ }^{2}$

When multiple target tissues for vitamin $\mathrm{D}$ (short for $1,25(\mathrm{OH})_{2}$ vitamin $D_{3}$ ) were discovered ${ }^{3}$ in all organ systems with an unconventional histochemical method, receptor microscopic autoradiography, ${ }^{4}$ the results clashed with those from common biochemical homogenates. ${ }^{5-7}$ The extensive histochemical data were ignored. A few biochemical in vitro studies followed and confirmed some of the pituitary and skin observations. In essence, the unexpected discoveries were met with initial silence and antagonism, which much later slowly turned into acceptance while still ignoring the original discoveries. Such scientific progression is a textbook example of the epistemological analysis of unexpected discoveries. ${ }^{8}$

Experiments with calcium-binding protein appeared to strengthen the vitamin $D$ calcium link, until comparisons revealed that calbindin sites did not match vitamin D nuclear binding shown in autoradiographic target distribution. Calcium-binding protein accordingly lost importance as a way to support the calcium concept. Similarly, recent studies with calcium-sensing receptor, assumed to be related to vitamin D sites of action, ${ }^{9}$ are unlikely to strengthen the vitamin D calcium concept. Comparisons indicate different distributions of calcium-sensing receptor and vitamin D target sites. Furthermore, skeletal and smooth muscle, both highly dependent on calcium, are not genomic targets in rodent experiments, as would be expected with the concept of calcitropic tissue regulation.

By 1995 over 50 target tissues for vitamin D had been reviewed, ${ }^{2}$ thus challenging the general concept of calcium homeostasis. As repeatedly emphasized, the hormone of sunshine's main action is not calcium homeostasis but rather a holistic concept: the regulation of vital functions, adaptation to the solar environment and maintenance of life. ${ }^{10,11}$ To be sure, calcium metabolism is part of it, especially related to growth and bone repair. But recently, other developments in the vitamin D field have also supported a much wider main role for vitamin $D$. This now includes strong epidemiological evidence for relationships between latitude and occurrence of diseases. An important contribution has also come from improved blood assays of vitamin $D$ metabolites. This blood work has led to the recognition that the fear of vitamin $D$ toxicity

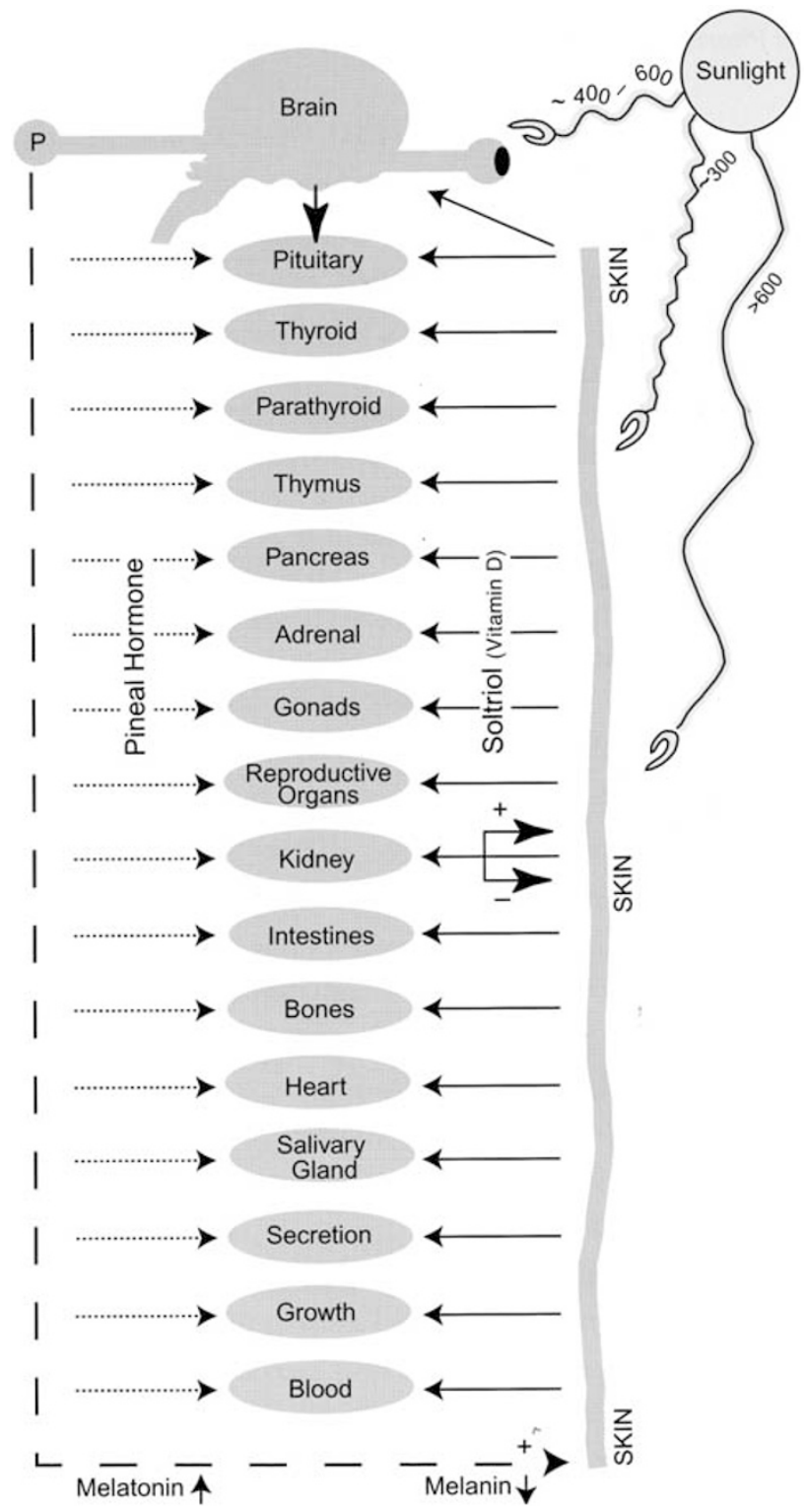

Figure 1. A holistic view of vitamin $D$ polyfunctional genomic targets (red) with associated effects from different wavelengths of sunlight, including temperature and visible light-related eye-pineal hormone. This schematic was published in 1988. It emphasizes not only the extensive vitamin D effects, but also the involvement of visible light and temperature, the role of melanin and especially melatonin, all of which need to be considered in the evaluation of biological effects of sunshine and vitamin $D$, renamed soltriol by the author. ${ }^{10,11,24}$ The color reproduction of this figure is available at the European Journal of Clinical Nutrition online. 
through calcification is unfounded and that high $25(\mathrm{OH})$ vitamin $D_{3}$ blood levels are well tolerated and even salubrious (emphasized by Dr Cannell, Vitamin D Council). ${ }^{12}$

The books are not yet closed. The calcium doctrine lingers on. Many of the target tissues demonstrated 20-30 years ago are still to be studied. This includes the brain and spinal cord, pituitary, adrenal medulla, stomach gland isthmus cells, pyloric muscle, heart atrial muscle, male and female reproductive organs and others. Many questions remain, such as why are low-dose effects different from high-dose effects and what are the related thresholds? ${ }^{13}$ What governs the expression of receptors? What is the meaning of the hierarchy of receptor occupation and target kinetics? What is the interaction between vitamin D and sex and adrenal steroids? Does vitamin D support seasonal and lifetime development, adjusting target concentrations during different phases?

From the distribution of target tissues and related effects, vitamin $\mathrm{D}$ can be considered a

\author{
'hormone of reproduction and fertility', ${ }^{14}$ \\ 'hormone of growth and development', ${ }^{15-17}$ \\ 'hormone of immune and stress response', ${ }^{18,19}$ \\ 'hormone of the digestive system', \\ 'hormone of endocrine regulation' \\ 'hormone of central nervous functions'. ${ }^{21-23}$
}

There is no evidence to distinguish between 'classical' and 'nonclassical' vitamin D target tissue und actions. The prevailing action and related designations depend on the status of the individual. The functions are linked to age and conditions, albeit all or most functions are active, more or less, at the same time. However, as evident from the scientific history, the designation of vitamin D's main functions has depended foremost on the focus of the investigator. And yet the whole picture must be kept in mind, and the scientific trap avoided when diligently studying parts. Furthermore, under natural conditions the sunshine hormone vitamin $D$ is not acting in isolation, but in concert with effects from other wavelengths of sunshine, as proposed in the1988 diagram (Figure 1). ${ }^{2}$

Vitamin $D$ is exceptional because of its extensive multiple actions, its high tolerance and its prophylactic and therapeutic potentials. Vitamin D's wide-ranging life-sustaining effects set it apart from other steroids, as well as all other compounds and drugs. Vitamin $D$ is as fundamental as the sun, the closest we have to a 'panacea'.

\section{CONFLICT OF INTEREST}

The author declares no conflict of interest

WE Stumpf

University of North Carolina, Chapel Hill, NC, USA

E-mail: stumpfwe@email.unc.edu

\section{REFERENCES}

1 Dupuis. The origin of all religious worship. New Orleans, 1872.

2 Stumpf WE. Vitamin D sites and mechanisms of action: a histochemical perspective. Reflections on the utility of autoradiography and cytopharmacology for drug targeting. Histochem Cell Biol 1995; 104: 417-427.

3 Stumpf WE, Sar M, Reid FA, Tanaka Y, DeLuca HF. Target cells for 1,25-dihydroxyvitamin D3 intestinal tract, stomach, kidney, skin, pituitary, and parathyroid. Science 1979; 7206: 1188-1190.

4 Stumpf WE. Drug Localization in Tissues and Cells. IDDC Press (University Bookstore): Chapel Hill, NC, 2003.

5 Colston K, Hirt M, Feldman D. Organ distribution of the cytoplasmic 1,25-dihydroxycholecalciferol receptor in various mouse tissues. Endocrinol 1980; 107: 1916-1922.

6 Gelbard HA, Stern PH, U'Prichard DC. 1 alpha, 25-Dihydroxyvitamin $D_{3}$ nuclear receptors in pituitary. Science 1980; 209: 1247-1249.

7 Sandgren ME, Brönnegärd M, DeLuca HF. Tissue distribution of the 1,25dihydroxyvitamin D3 receptor in the male rat. Biochem Biophys Res Commun 1991; 181: 611-616.

8 Kuhn TS. The Structure of Scientific Revolution. University of Chicago Press: Chicago, 1962

9 Peterlik M, Cross HS. Vitamin D and calcium insufficiency-related chronic diseases: molecular and cellular pathophysiology. Eur J Clin Nutr 2009; 63: 1377-1386.

10 Stumpf WE. The endocrinology of sunlight and darkness. Complementary roles of vitamin D and pineal hormones. Naturwissenschaften 1988; 75: 247-251.

11 Stumpf WE. The main role of vitamin D: seasonal regulation of vital functions. High-resolution target recognition leads to a new paradigm and advanced drug development. Eur J Drug Metab Pharmacokinet 2007; 32: 1-6.

12 Vieth R. Vitamin D supplementation, 25-hydroxyvitamin D concentrations, and safety. Am J Clin Nutr 1999; 69: 842-856.

13 Stumpf WE. The dose makes the medicine. Drug Discov Today 2006; 11: 550-555.

14 Stumpf WE, Denny ME. Vitamin D (soltriol), light, and reproduction. Am J Obstet Gynecol 1989; 161: 1375-1384.

15 Narbaitz R, Stumpf WE, Sar M, Huang S, DeLuca HF. Autoradiographic localization of target cells for 1 alpha, 25-dihydroxyvitamin D3 in bones from fetal rats. Calcif Tissue Int 1983; 35: 177-182.

16 Stumpf WE, Sar M, Narbaitz R, Huang S, DeLuca HF. Autoradiographic localization of 1,25-dihydroxyvitamin D3 in rat placenta and yolk sac. Horm Res 1983; 18: 215-220.

17 Stumpf WE, Koike N, Hayakawa N, Tokuda K, Nishimiya K, Tsuchiya Y et al. 1,25-Dihydroxyvitamin D3 and 22-oxa-1,25-dihydroxyvitamin D3 in vivo nuclear receptor binding in developing bone during endochondral and intramembranous ossification. Histochemistry 1994; 102: 183-194.

18 Stumpf WE, Downs TW. Nuclear receptors for $1,25(\mathrm{OH}) 2$ vitamin D3 in thymus reticular cells studied by autoradiography. Histochemistry 1987; 87: 367-369.

19 Puchacz E, Stumpf WE, Stachowiak EK, Stachowiak MK. Vitamin D increases expression of the tyrosine hydroxylase gene in adrenal medullary cells. Brain Res Mol Brain Res 1996; 36: 193-196.

20 Stumpf WE. Vitamin D and the digestive system. Europ J Drug Metabol Pharmacokinet 2008; 33: 85-100.

21 Stumpf WE, O'Brien LP. 1,25 (OH)2 vitamin D3 sites of action in the brain. An autoradiographic study. Histochemistry 1987; 87: 393-406.

22 Stumpf WE. Drugs in the brain--cellular imaging with receptor microscopic autoradiography. Prog Histochem Cytochem 2012; 47: 1-26.

23 Gominak SC, Stumpf WE. The world epidemic of sleep disorders is linked to vitamin D deficiency. Med Hypotheses 2012; e-pub ahead of print 12 May 2012.

24 Stumpf WE. Vitamin D--soltriol the heliogenic steroid hormone: somatotrophic activator and modulator. Discoveries from histochemical studies lead to new concepts. Histochemistry 1988; 89: 209-219. 